\title{
Research on Prediction of Land Use Change in Central Cities of Southern Yunnan Based on Markov Model
}

\author{
Shijie Tao ,Shanghai Tongji urban planning \& design institute CO.,LTD.,China \\ Xiaoyou Wen , Shanghai Tongji urban planning \& design institute CO.,LTD.,China \\ Shimin Li Honghe Prefecture Natural Resources and Planning Bureau,China
}

\begin{abstract}
The central city of southern Yunnan is located in the Hani Yi Autonomous Prefecture of Honghe, Yunnan Province, and consists of three cities: Mengzi City, Kaiyuan City and Gejiu City. The central city of southern Yunnan has obvious characteristics of natural elements such as large altitude difference, obvious topography, and rich and diverse climate. Land simulation is one of the important technical means to predict the future trend and direction of urban development. Generally, by calculating the probability of land use conversion over the years, selecting factors influencing urban development, and constructing a land prediction model. This paper uses the 2009 and 2014 land use data as the base year data, and divides the land types into 8 categories: cultivated land, forest land, garden land, agricultural land, construction land, water area, unused land and grassland, using Marko in IDRISI 17.0 The husband model obtains the increase or decrease of each land use type and the conversion probability of each land use type, predicts the spatial distribution of the land use type in 2016 through the conversion matrix, and uses the 2016 land use type to verify the kappa coefficient to simulate and predict southern Yunnan The spatial distribution of land types in central cities in 2035. Through permanent basic farmland, ecological protection red line, water area and other prohibitive factors, and restrictive factors such as topography and landform, soil type, night light index and other restrictive factors, the central city of southern Yunnan will be simulated and predicted by multiple scenarios in 2035, and land use types under each scenario will be increased Analysis of the reduction situation, in-depth study of the impact of different scenario simulations on the future development direction and spatial pattern of the city, in order to provide a reference for the future development direction of the city and the layout of construction land.
\end{abstract}

\section{Keywords}

land prediction, Markov model, multi-scenario simulation

\section{Introduction}

The central city of southern Yunnan covers the three cities of Mengzi, Kaiyuan and Gejiu. Located in the southeast of Yunnan Province, it plays an important role in the "two corridors and one circle" strategy and cross-border cooperation between China and Vietnam. Mode, the contradiction between urban industrialization and urbanization needs of land resources and ecological environment protection is gradually increasing. Therefore, how to coordinate the contradiction between urban development and 
land has become a problem that must be considered in the development of the central city in southern Yunnan. Therefore, this paper uses the CA-Markov model to simulate and predict the land use type of Honghe Prefecture in 2035 under multiple scenarios based on the land use data over the years, comprehensively analyze the land use change trend in terms of spatial distribution and scale, and formulate a reasonable land use for the central city in southern Yunnan. Provide support for spatial master planning and urban development.

\section{Situation of the study area}

The central city of southern Yunnan is located in the southeastern part of Yunnan Province. It is an important node of the country's "One Belt, One Road" construction and an important frontier of Yunnan's construction facing the radiation center of South Asia and Southeast Asia. The central city of southern Yunnan has a total administrative area of 5834 square kilometers and a total population of $1,286,200$ in 2019 . The urban permanent population is 958,800 , the urbanization rate is $74.55 \%$, and the core area is 596 square kilometers.

\section{Data sources and processing research methods}

\subsection{Data source and processing}

This paper selects the 2009 land use data as the base year data, the 2014 land use data as the final data, and the 2016 land use data as the verification data. The land use data is rasterized, and the raster resolution is $30 \mathrm{~m} * 30 \mathrm{~m}$. The land use types are divided into 8 categories: cultivated land, forest land, garden land, agricultural land, construction land, water area, unused land and grassland.

\subsection{Research methods}

The Markvo model is a method for predicting the occurrence probability of events based on the Markov process theory. When the land use type transfer rate is relatively stable, the Markvo model can be used to predict the land use type when making long-term predictions of land use changes. The area and proportion of the transfer. In this paper, the CA-Markvo model of Markov theory is used to construct a future land use prediction model to simulate and analyze the whole area of Honghe State, and to predict the spatial evolution trend of land demand in Honghe State.

\section{Results and analysis}

\subsection{Characteristics of land use changes in Honghe Prefecture from 2009 to 2014}

Calculating the area of different land use types in 2009 and 2014 (Table 6-16), it can be seen that in 6 years, construction land was mainly converted from cultivated land and garden land, of which construction land increased by 20.31 square kilometers and cultivated land decreased. 12.20 square kilometers, the garden area has been reduced by 7.10 square kilometers. The increase in construction land was mainly concentrated in the northern area of Wenlan Town and the southern area of Yuguopu Town. There was also a small increase in construction land within Datun Sub-district.

Figure 4-1 Land use map in 2009 and 2014

Table 4-1 Land use area change table in 2009 and 2014 (unit: square kilometers) 


\begin{tabular}{|c|c|c|c|}
\hline Land type & Year 2009 & Year 2014 & Change value \\
\hline arable land & 275.54 & 263.34 & -12.20 \\
\hline woodland & 29.63 & 29.13 & -0.50 \\
\hline Garden & 104.82 & 97.72 & -7.10 \\
\hline Agricultural land & 12.80 & 12.91 & 0.11 \\
\hline Construction land & 101.30 & 121.60 & 20.31 \\
\hline Waters & 32.29 & 32.21 & -0.08 \\
\hline Unused land & 24.04 & 23.84 & -0.20 \\
\hline grassland & 15.49 & 15.15 & -0.34 \\
\hline
\end{tabular}

\subsection{Selection of influencing factors}

Due to the mutual influence between natural and human elements in different time and space ranges, the land use change in the core area of the central city in southern Yunnan has been formed. The productivity of land resources is mainly affected by natural factors such as slope and elevation; while the transformation of land use types is affected by the behavior of local economic development and other entities. Therefore, the influencing factors selected for this topic in the study of central cities in southern Yunnan are shown in the following table.

Table 4-2 Land use type classification table

\begin{tabular}{|c|c|c|}
\hline \multicolumn{2}{|c|}{ Model factors } & Data Sources \\
\hline \multicolumn{2}{|c|}{ slope } & \multirow{2}{*}{ Geospatial Data Cloud } \\
\hline \multirow{2}{*}{ Elevation } & highway & \multirow{2}{*}{ Open Street Map } \\
\cline { 2 - 2 } transportation & railway & \multirow{2}{*}{ First-class highway } \\
\cline { 2 - 2 }
\end{tabular}

\subsection{Generate land use type transition probability matrix}

Select the MARKOV tool in IDRISI, use the 2009 data as the firstland data, the 2014 land use as the secondland data, and fill in 2 for the forecast year (that is, the year separated from the 2016 land use data), and finally output the transition probability matrix.

Table 4-3 Probability Matrix of Land Use Transition under General Situation(To 2016)

\begin{tabular}{|c|c|c|c|c|c|c|c|c|}
\hline & CI.1 & CI.2 & CI.3 & CI.4 & CI.5 & CI.6 & CI.7 & CI.8 \\
\hline Class1 & 0.8214 & 0.0000 & 0.0000 & 0.0089 & 0.1786 & 0.0000 & 0.0000 & 0.0000 \\
\hline Class2 & 0.0000 & 0.8358 & 0.0000 & 0.0024 & 0.1618 & 0.0000 & 0.0000 & 0.0000 \\
\hline Class3 & 0.0000 & 0.0000 & 0.7924 & 0.0061 & 0.2015 & 0.0000 & 0.0000 & 0.0000 \\
\hline Class4 & 0.0000 & 0.0000 & 0.0000 & 0.8026 & 0.1974 & 0.0000 & 0.0000 & 0.0000 \\
\hline Class5 & 0.0000 & 0.0000 & 0.0000 & 0.1502 & 0.8498 & 0.0000 & 0.0000 & 0.0000 \\
\hline Class6 & 0.0000 & 0.0000 & 0.0000 & 0.0016 & 0.1506 & 0.8478 & 0.0000 & 0.0000 \\
\hline Class7 & 0.0000 & 0.0000 & 0.0000 & 0.0007 & 0.1565 & 0.0000 & 0.8428 & 0.0000 \\
\hline Class8 & 0.0000 & 0.0000 & 0.0000 & 0.0009 & 0.1676 & 0.0000 & 0.0000 & 0.8315 \\
\hline
\end{tabular}




\subsection{Simulation of land change in $\mathbf{2 0 3 5}$}

\subsubsection{Land change simulation}

This paper uses the 2009 data as the base year land data and the 2014 data as the last year land data. The land transition probability matrix calculated by IDRISI17.0 and the suitability map set are used as the basis for the land simulation. Iterated twice to obtain the land use in 2035. data.

Due to the mutual influence between natural elements and human elements in different time and space ranges, land use changes are formed. The productivity of land resources is mainly affected by natural factors such as slope and elevation; while the transformation of land use types is affected by the behavior of local economic development and other subjects. Therefore, in the research process, this paper selects terrain, traffic and other influencing factors to make a suitability atlas.

\subsubsection{Land simulation accuracy test}

This paper uses the Cross tab tool in IDRISI 17.0 to test the accuracy of the 2016 simulated land use data. The Kappa coefficient is generally used for consistency testing. Usually the result falls between $0-1$. The larger the value, the higher the accuracy of the simulation. Among them, $0.0-0.20$ is a very low consistency (slight), $0.21-0.40$ is a general consistency (fair), $0.41 \sim 0.60$ is a moderate consistency (moderate), $0.61-0.80$ is a high consistency (substantial) and $0.81-1$ is almost perfect. The kappa coefficient simulated in this paper is 0.8724 , and the coefficient value is greater than $85 \%$, which is almost the same level. The simulation accuracy is good, and it can meet the forecast and analysis of the land use pattern in 2035.

\subsection{Forecast of Land Use Change in 2035}

\subsubsection{Land use prediction under general scenarios}

The above CA Markov model has high accuracy and can be used as a model for predicting land use types in 2035. Similarly, first calculate the land use transition probability matrix to 2035 and make a suitability atlas. The number of iterations is set to 21 , and finally Generate a land use type map of in 2035. 


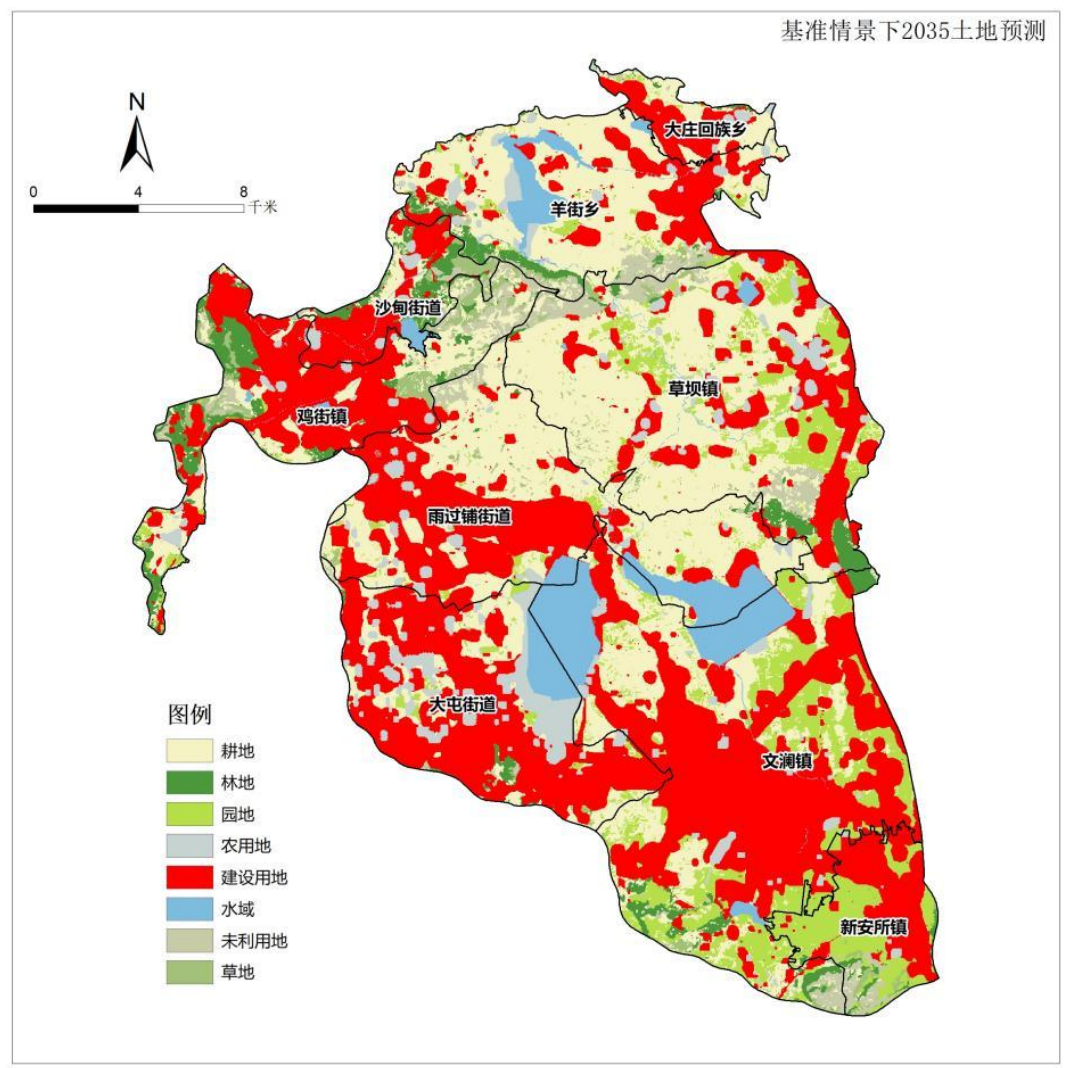

Figure 4-2 Land use simulation in 2035 under general scenarios

On the whole, under the baseline scenario, there is a clear trend of expansion of construction use in the core area to cultivated land. Construction land increased by 102.91 square kilometers. In terms of spatial distribution, construction land in Wenlan Town, Datun New District, Jijie Shadian area, and Wenlan Town have expanded to a greater extent. Construction land is mainly transformed from cultivated land and garden land, and the degree of urban-rural integration is further strengthened.

Table4-3 Statistical table of predicted land use changes in 2035 under general scenarios (unit: square kilometers)

\begin{tabular}{|c|c|c|c|}
\hline Land type & 2019 year & Forecast for 2035 & Change value \\
\hline arable land & 220.03 & 197.27 & -22.76 \\
\hline woodland & 52.94 & 23.57 & -29.37 \\
\hline Garden & 103.61 & 68.95 & -34.66 \\
\hline Agricultural land & 25.56 & 31.36 & 5.80 \\
\hline Construction land & 127.85 & 230.75 & 102.91 \\
\hline Waters & 34.42 & 32.21 & -2.21 \\
\hline Unused land & 6.90 & 19.79 & 12.89 \\
\hline grassland & 14.20 & 12.27 & -1.93 \\
\hline
\end{tabular}




\subsubsection{Land use prediction under ecological priority scenarios}

On the basis of the general scenario, set the restrictive factors as the ecological protection red line and water area, ensure that the development of urban construction land is far away from the ecological protection area, and select the CA_MARKOV tool, select the land use data in 2014, and fill in the transfer matrix file and Suitability atlas file to finally generate predicted land use data for 2035.

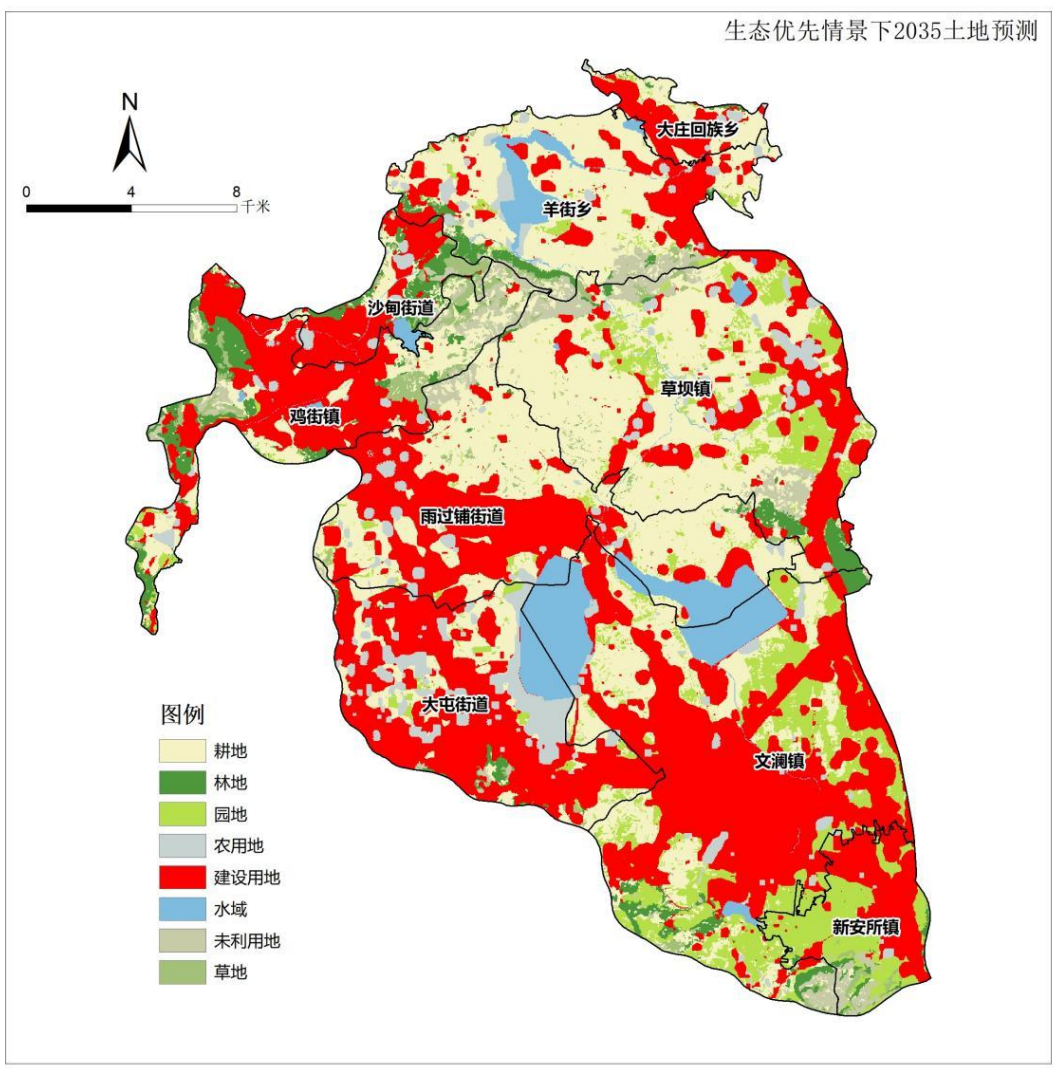

Figure 4-3 Prediction of land use in 2035 under ecological priority scenarios

Compared with general scenarios, urban development is restricted within a certain space. Due to the small scale of the ecological protection red line in the core area, the expansion of construction land under the ecological priority scenario is less restrictive.

Table4-4 Forecast table of newly added construction land in 2035 under the ecological priority scenario (unit: square kilometers)

\begin{tabular}{|c|c|c|c|c|c|c|}
\hline $\begin{array}{c}\text { Township } \\
\text { name }\end{array}$ & 2019 year & \multicolumn{2}{|c|}{ General situation } & \multicolumn{2}{|c|}{$\begin{array}{c}\text { Ecological priority } \\
\text { scenario }\end{array}$} & Compared with the general \\
for 2035 & $\begin{array}{c}\text { New } \\
\text { value- } \\
\text { added }\end{array}$ & $\begin{array}{c}\text { Forecast } \\
\text { for 2035 }\end{array}$ & $\begin{array}{c}\text { New } \\
\text { value- } \\
\text { added }\end{array}$ & $\begin{array}{c}\text { decline } \\
\text { situan }\end{array}$ \\
\hline Jujie Town & 13.37 & 25.57 & 12.20 & 25.43 & 12.06 & rise \\
\hline $\begin{array}{c}\text { Shadian } \\
\text { Jiedao }\end{array}$ & 6.36 & 8.42 & 2.06 & 8.61 & 2.25 & rise \\
\hline $\begin{array}{c}\text { Rain over } \\
\text { paved } \\
\text { streets }\end{array}$ & 19.27 & 33.63 & 14.36 & 34.15 & 14.88 & decline \\
\hline $\begin{array}{c}\text { Datun } \\
\text { Jiedao }\end{array}$ & 26.38 & 39.81 & 13.43 & 38.43 & 12.05 & rise \\
\hline $\begin{array}{c}\text { Wenlan } \\
\text { Town }\end{array}$ & 45.65 & 68.61 & 22.96 & 69.48 & 23.83 & \\
\hline
\end{tabular}




\begin{tabular}{|c|c|c|c|c|c|c|}
\hline $\begin{array}{c}\text { Xin'ansuo } \\
\text { Town }\end{array}$ & 5.52 & 11.93 & 6.41 & 11.62 & 6.10 & decline \\
\hline Caoba Zhen & 1.54 & 23.55 & 22.01 & 24.08 & 22.54 & rise \\
\hline $\begin{array}{c}\text { Dazhuang } \\
\text { Huizu } \\
\text { Township }\end{array}$ & 2.04 & 5.60 & 3.56 & 5.69 & 3.65 & decline \\
\hline $\begin{array}{c}\text { Yangjie } \\
\text { Xiang }\end{array}$ & 7.72 & 13.63 & 5.91 & 13.27 & 5.55 & -- \\
\hline total & 127.85 & 230.75 & 102.91 & 192.33 & 102.91 & - \\
\hline
\end{tabular}

\subsubsection{Prediction of land use under food security scenarios}

On the basis of the baseline scenario, set the restrictive factors as permanent basic farmland and water area, and select the CA_MARKOV tool, select the 2014 land use data, and fill in the transfer matrix file and the suitability atlas file to finally generate the forecast Land use data in 2035 . The permanent basic farmland in the core area is mainly distributed in Caoba Town, Dazhuang Hui Township and Xin'ansuo Town. The permanent basic farmland restricts the expansion of future construction land and retains the concentration of cultivated land. 


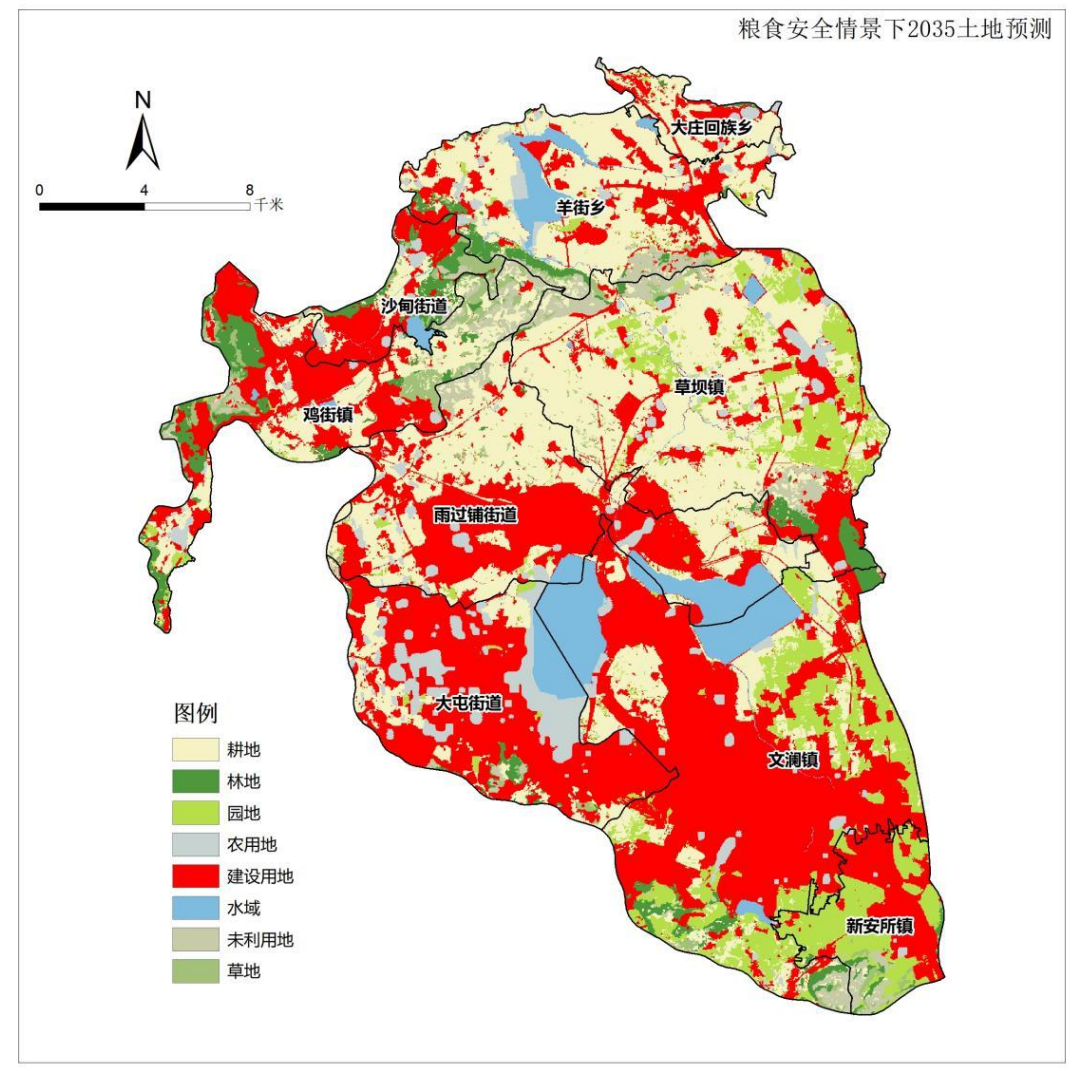

Figure 4-4 Prediction of Land Use in 2035 under Food Security Scenario

Table4-5 Forecast table of newly added construction land under food security in 2035 (unit: square kilometers)

\begin{tabular}{|c|c|c|c|c|c|c|}
\hline \multirow{2}{*}{$\begin{array}{c}\text { Township } \\
\text { name }\end{array}$} & 2019 year & \multicolumn{2}{|c|}{ General situation } & \multicolumn{2}{|c|}{$\begin{array}{c}\text { Ecological priority } \\
\text { scenario }\end{array}$} & Compared with the general \\
\cline { 2 - 6 } & Forecast & $\begin{array}{c}\text { New } \\
\text { value- } \\
\text { for } 2035\end{array}$ & $\begin{array}{c}\text { Forecast } \\
\text { for } 2035\end{array}$ & $\begin{array}{c}\text { New } \\
\text { value- } \\
\text { added }\end{array}$ & decline \\
\hline Jujie Town & 13.37 & 25.43 & 12.06 & 21.34 & 7.97 & decline \\
\hline $\begin{array}{c}\text { Shadian } \\
\text { Jiedao }\end{array}$ & 6.36 & 8.61 & 2.25 & 8.08 & 1.72 & rise \\
\hline $\begin{array}{c}\text { Rain over } \\
\text { paved } \\
\text { streets }\end{array}$ & 19.27 & 34.15 & 14.88 & 35.63 & 16.36 & rise \\
\hline $\begin{array}{c}\text { Datun } \\
\text { Jiedao }\end{array}$ & 26.38 & 38.43 & 12.05 & 40.46 & 14.08 & rise \\
\hline $\begin{array}{c}\text { Wenlan } \\
\text { Town }\end{array}$ & 45.65 & 69.48 & 23.83 & 77.20 & 31.55 & decline \\
\hline $\begin{array}{c}\text { Xin'ansuo } \\
\text { Town }\end{array}$ & 5.52 & 11.62 & 6.10 & 10.58 & 5.06 & decline \\
\hline Caoba Zhen & 1.54 & 24.08 & 22.54 & 20.11 & 18.57 & decline \\
\hline $\begin{array}{c}\text { Dazhuang } \\
\text { Huizu } \\
\text { Township }\end{array}$ & 2.04 & 5.69 & 3.65 & 3.41 & 1.37 & \\
\hline
\end{tabular}




\begin{tabular}{|c|c|c|c|c|c|c|}
\hline $\begin{array}{c}\text { Yangjie } \\
\text { Xiang }\end{array}$ & 7.72 & 13.27 & $\mathbf{5 . 5 5}$ & 13.88 & $\mathbf{6 . 2 3}$ & rise \\
\hline total & 127.85 & 192.33 & 102.91 & 230.69 & 102.91 & - \\
\hline
\end{tabular}

4.6.The Guiding Significance of Land Use Simulation to the Overall Planning of Territorial

\section{Space}

Scientific, objective and reasonable simulation of land use can not only grasp its change and development laws, but also simulate the trend of future land changes in the study area. According to the simulation, by 2035, the city will expand rapidly and the degree of urban integration will be strengthened.

According to the requirements of the urban development strategy of Honghe Prefecture, the economic strength of the state will be greatly improved by 2035, and the per capita GDP and the proportion of middle-income groups will reach the average level of the province. At the same time, a modern industrial system will be established, and the innovation and competitiveness of economic development will be fully enhanced. The development of urban and rural areas is more balanced, and the ability of central cities to radiate and drive is significantly enhanced; the quality of the ecological environment is higher than the national average; infrastructure such as transportation is fully connected to the Internet; the level of open development is significantly improved, becoming an important engine for economic transformation and growth in Yunnan Province. Competitive modern national state. Therefore, in the land and space planning of Honghe Prefecture, it is necessary to formulate a reasonable land policy, strictly control the land, achieve high-quality and economical development of land, vigorously develop transportation infrastructure construction, narrow the gap between the North and the South, and reduce the problem of disorderly expansion of cities in the northern region.

\section{Conclusion and shortcomings}

This paper uses ArcGIS spatial statistics tools to analyze the spatial change characteristics and quantitative scale change trends of various land types from 2000 to 2014. And select traffic, topography, water area, ecological protection red line, and permanent basic farmland as the influencing factors, use the Markov model in IDRISI software to calculate the transition probability of each land type, make a suitability atlas, and use the CA Markov model to predict the land in 2035 Use patterns. The main conclusions are as follows:

(1)The central city of southern Yunnan has the largest proportion of forest land and cultivated land. From 2009 to 2014, Honghe Prefecture continued to develop its social economy, and some cultivated land and garden land were converted into construction land. Government departments should strengthen the deepening of land management and control content in the process of preparing land and space plans. , To formulate reasonable control rules to prevent the disorderly expansion of the city.

(2)The results of the land use simulation model are highly accurate. The CA Markov model is constructed by selecting influencing factors such as traffic and terrain. The kappa coefficient of the calculated model is 0.8724 , which is between $0.8-1.0$. The consistency is high and the simulation accuracy of the model is high.

(3)The spatial distribution of land under different scenarios is different. Under the general scenario, urban development is not restricted by policy factors, urban expansion speeds up, and the scale of construction land increases significantly; under the ecological priority scenario, urban development is limited; under the food security scenario, permanent basic farmland is obtained Better protection, the scale of agricultural production is guaranteed, and the expansion of construction land is restricted.

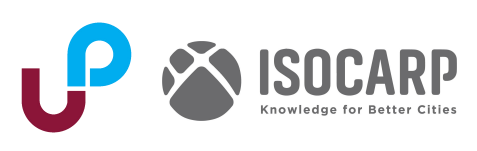


(4)The land simulation model constructed in this article can be used as one of the important models of the "One Map" implementation supervision information platform for Honghe Prefecture's land and space planning. It is used for resource and environmental carrying capacity evaluation, natural resource monitoring, evaluation, early warning, and regional development trend research and judgment. The provision of tool support and method reference will promote the improvement of the work level of Honghe Prefecture's territorial and spatial planning, implementation, monitoring, evaluation and early warning.

Although in the process of simulating land use, this paper selects factors such as traffic, water area, topography, etc., but there are still insufficient considerations. We should consider the actual development of the local area, and consider the impact of policies and natural environment on land changes, and select unsuitable areas for urban construction. , Historical and cultural protection and other factors to improve the accuracy of land simulation prediction.

\section{References}

[1]Turner B.L.II,D.skole, G.Fisher,L.Freso and R.Leemans,ed.Land -use and land -cover change:science/res earch plan.IGBP Report No.35 and HDP Report No.7. stockholm and Geneva,1995.

[2]Hou Lisheng, Cai Yunlong.Substantial analysis and progress review of land use/cover change research.P rogress in Geographical Sciences.2004(6),p96-104.

[3]Ran Yuju.Simulation and prediction of land use change in Banan District based on CA-Markov mode.An hui Agricultural Science Bulletin,2021,27(11),125-130.

[4]Zhao Hui,Chen Changyong.Verification and Modification Analysis of FLUS Model for Suitability Evaluati on of Foshan's Urban Construction.Planners,2020(3),86-92.

[5]Sun Yizhong, Yang Jing, Song Shuying et al. Multi-level vector cellular automata modeling and land use change simulation. Acta Geographica Sinica,2020,75(10),2164-2179.

[6]Zhao Xuan, Peng Jiandong, Fan Zhiyu, et al. Research on Land Use Simulation and Urban Development Boundary Delineation of Wuhan Metropolitan Area Based on FLUS Model from the Perspective of "Doubl e Evaluation".Journal of Geo-Information Science,2020,22(11),2212-2226.

[7]Zhang Xiaorong, Li Ainong, Nancy, et al. Multi-scenario simulation of land use change in China-Pakistan Economic Corridor based on the coupling of FLUS model and SD model.Journal of Geo-Information Scien ce,2020,22 (12),2393-2409.

[8]Chen Guang. Evaluation of land use data based on CA-Markov in the simulation of urban heat island eff ect.Building Science,2021,37(2),113-120. 